\title{
FUZZY LOGIC AND ARTIFICIAL INTELLIGENCE TOOLS IN THE CONTEXT OF TOURISM ANALYSIS
}

\author{
Simona Hašková ${ }^{1}$ (i) \\ Jakub Horák ${ }^{2}$ (D)
}

DOI: https://doi.org/10.31410/tmt.2020.601

\begin{abstract}
Qualitative and quantitative approaches to multicriteria evaluation and managerial decision-making often ignore the specifics of the role of the human factor. This article summarizes management methods that reflect not only numerical inputs but also data of a qualitative nature while considering their applicability in the tourism sector. Some of them can be assorted within the classes of Artificial intelligence. The focus is on the fuzzy approach at the theoretical and application level. The fuzzy approach is used to evaluate the degree of country travel and tourism competitiveness of selected European and Asian countries based on subjective rankings from the viewpoint of travelling persons. The results indicate that among countries under review, China is ranked as a highly competitive country in travel \& tourism. Conditional competitive countries in terms of travel \& tourism are the Czech Republic, Pakistan, Russia, and Turkey.
\end{abstract}

Keywords: Decision making, Artificial neural networks, Six sigma, Forecasting, Fuzzy approach.

\section{INTRODUCTION}

Q tandard mathematical approaches to multicriteria evaluation and managerial decision-makSing largely based on it more or less ignore the specifics of the human factor role in evaluation and decision-making activities in terms of individual knowledge, skills, and experience of decision-makers. These standard approaches make managers not deviate from the framework of a deep-rooted tradition of scientific thinking, which identifies understanding a phenomenon with the ability to quantitatively analyse it as if it was a mechanistic system subjected to algebraic, differential or integral equations. In this context, see e.g. the study by Jovanović (1999), who deals with investment decision-making in conditions of uncertainty and risk using standard methods like Break-even Analysis, Sensitivity Analysis, Theory of Games, and Decision Making Theory, or Schwartz \& Zozaya-Gorostiza (2002), who perform investment evaluation in disruptive technologies in a conventional way. Many decision tools and techniques have been developed to assist managers in making decisions in conditions of uncertainty while reflecting human vague thinking (Coldrick et al., 2005).

Decision tools are important instruments for setting business strategies. It is the quality of the individual corporate processes, which is key for maintaining stability and competitiveness. From the historical point of view, the first tool of quality management is Statistical quality control (SQC). However, much more commonly used methods, which could be referred to as classical ones, are Total quality management, Six Sigma, and a new concept of Six Sigma - Lean Six Sigma (LSS). These methods are widely used in industries, and an important question to

Institute of Technology and Business in Ceske Budejovice, School of Expertness and Valuation, Okruzni 517/10, 37001 Ceske Budejovice, Czech Republic

2 Institute of Technology and Business in Ceske Budejovice, School of Expertness and Valuation, Okruzni 517/10, 37001 Ceske Budejovice, Czech Republic 
be asked is to what extent these methods are applicable in the tertiary sector, e.g. in tourism. With the development of computer technologies in the last decades, new management methods have appeared, which are based on cybernetic principles. Some of them can be assorted within the classes of Artificial intelligence (AI) that emerged as a computer science discipline in the 1950s. Many powerful tools have been developed that are useful for automatically solving systems that would otherwise require human intelligence. These tools include knowledge systems, fuzzy logic (Omrane et al., 2016), inductive learning, neural networks, genetic algorithms, case reasoning, ambient intelligence, analytical hierarchy and network process (Sevinc et al., 2018). These techniques can be used independently or in a combination; they can handle both the numerical inputs and linguistic variable. A critical point is to choose a structured approach that will help decision-makers formulate their judgments and attitudes.

In the task of expert analysis or expert management of vaguely defined systems, the vague concepts are usually presented by means of linguistic variables and their linguistic values (i.e., terms). The word "linguistic" is used here in the meaning "communicated in natural language". Desirable relationships between combinations of terms of input linguistic variables and terms of an output linguistic variable are given by a set of rules. The fuzzy set theory and the fuzzy approach based on it serves this purpose very well.

The fuzzy approach provides space for application of the human factor (individual knowledge, skills, and experience of an expert). It is based on the assumption that key elements of human thinking are not numbers, but intuitive concepts, the contents of which can be modelled by fuzzy sets, i.e. sets with blurred edges in which the transition from the membership to "non-membership" is gradual and vague rather than sudden and sharp (Zadeh, 1999). The ubiquity of fuzziness in the processes of human thinking suggests that most of the logic behind it is the logic with continuous fuzzy truths, fuzzy connections, and fuzzy derivation rules. The ability to manipulate intuitive concepts and subsequent summarization in the sense of summarizing data is one of the most important advantages of the human mind, which is also its fundamental characteristic (Zadeh, 1973).

The fuzzy method is used to evaluate the level of country travel \& tourism competitiveness based on the subjective rankings of Travel \& Tourism Policy and Enabling Conditions, Natural and Cultural Resources, and Safety and Security published by Calderwood \& Soshkin (2019) among selected European and Asian countries from the perception of travelling persons.

The objective of the paper is to evaluate the degree of country travel \& tourism competitiveness across European and Asian countries based on the subjective rankings from the viewpoint of travelling persons using fuzzy approach.

\section{LITERATURE REVIEW}

The following part briefly describes the basic methods and approaches to assess managerial tasks in situations of risk and uncertainty.

\subsection{Method of Statistical quality control as an initial tool of quality management}

The first analytical management tools were simple statistical methods - the so-called Statistical quality control (SQC). The modification of probability theory for the application in business enabled the introduction of the SQC system, the system that gave rise to a complex control system, 
and which enabled the regulation of costs and risks, improvement of manufacturing knowledge, and specification of the definition of quality. As such, it led to the creation of a specialized position, "Quality engineer" (Miranti, 2005). It may seem that currently, the SQC is less commonly used due to the existence of more sophisticated and modern measurement tools. According to Grigg \& Walls (2007), SQC has its relevant application (in the present as well as in the future) in the whole industry, provided that the management has basic statistical thinking. Boyapati \& Kantam (2012) agree with this statement, using also the analysis of graph of extreme values, which sorts the data into subsets, determines their extreme values, and further processes them using the probability theory.

\subsection{Total Quality Management}

Another classic management tool is Total quality management (TQM). Ghassan et al. (2019) seek a correlation between introducing the control mechanism TQM and the performance of companies operating in the service sector. If TQM is focused on customers and innovations, it has the potential to improve the performance of the company. Zhang et al. (2020) note that the quantitative use of TQM in the service sector is not very frequent; however, there have been recently more and more papers dealing with this issue. Especially managers of companies operating in the service sector should pay attention to new possibilities of the application of TQM. Well-implemented TQM should influence the so-called Critical Success Factors (CSF). For example, in the hospitality sector, the first rank of soft aspects includes internal and external cooperation, which is followed by focus on customer and effective management (Jusoh et al., 2018). Benavidez-Valesco et al. (2014) connect TQM and Corporate Social Responsibility (CSR) on the example of hotel services. The synthesis of TQM and CSR is a relevant philosophy of hotel management that generates a competitive advantage. The implementation results in the increased accommodation capacity and higher performance of a hotel as a business. The growing productivity of a hotel is given by the satisfaction of its employees (Tari et al., 2017).

\subsection{Contribution of Motorola - Six Sigma philosophy}

The aforementioned tools of quality management are mainly of historical significance, although their application, as stated above, is still suitable. The most popular tools to improve the management processes currently include Six Sigma $(6 \sigma)$. Its popularity has grown in recent decades (Sony et al., 2020; Ninerola et al., 2019). For successful implementation of this method in a company, it is necessary to accept its individual tools and the entire methodology in the organization. Also, it should be stated that the issue of the individual acceptance of Six Sigma is addressed in a relatively low number of research papers (Mueller \& Cross, 2020). Based on statistical evidence, it may be stated that the implementation of Six Sigma in a company increases the innovation activities (incremental innovation) and the overall financial performance of the company (Oprime et al., 2019). Six Sigma can be used to optimize skill-based processes, such as software development in IT industries (John \& Kadadevaramath, 2020). According to Cudney et al. (2020), Six Sigma can even be used to improve teaching methods at universities; however, this is conditioned by carrying out more complex studies. There is a relatively low number of papers dealing with the implementation of Six Sigma in the sector of public services. It is particularly the level of public transport that has a significant impact on the quality of the economic and social life in towns. A high level of urban public transport indicates the status of a modern town. The application of the Six Sigma method has the potential to contribute to the quality of public services (Kuvvetli \& Firuzan, 2019). Chakraborty \& Tan (2012) provide the 
basis for the successful application of Six Sigma in the services sector. The sample of tested entities includes also a hotel; however, the study is limited by a lower number of elements in the statistical dataset and locality (Singapore). Despite this, it can be argued that Six Sigma has the potential to influence contextual factors (e.g. type of services). In 2001, the company Starwood Hotels and Resorts was thinking about accepting the Six Sigma philosophy within the planned improvement of the quality of its services. The expected outcome was increased performance of hotels (Pearlman \& Chacko, 2012).

\subsection{Modification of Six Sigma - Lean Six Sigma}

At the beginning of the new millennium, Lean Six Sigma (LSS) evolved from Six Sigma. The basic principle of LSS is interconnecting the lean thinking principles, i.e. the elimination of waste, and the Six Sigma method. It can be said that in practice, LSS is widely introduced to improve the processes of health care; it helps to improve the operation and quality, reduce costs, and medical errors. The condition of the successful implementation of LSS in health care is knowing the level of entity preparedness for the transformation before the very beginning of the change (Vaishnavi \& Suresh, 2020). Gupta et al. (2020) bring an interesting view of the issue of leaving university early. With the help of university teachers and LSS experts, they try to find a solution to eliminate this negative phenomenon. There can also be mentioned the sector of public services, specifically the police as a security component of the state. It often has to face a limited budget. Adoption of LSS may lead to streamlining of the processes and better staff morale in reducing costs (Antony et al., 2019). Fletcher (2018) mentions the rich fund of LSS contributions aimed at the private sector. He tries to apply LSS in the public sector of services in the context of municipalities. There are also positive factors influencing the effective use of tax revenues, organizational structure, cost reduction. The adoption of LSS can thus theoretically have the potential to suppress the bureaucratic apparatus. Finally, a contribution from the service sector within the private sector. Gutierrez-Gutierrez et al. (2016) state that the combination of lean thinking and Six Sigma leads to continuous improvement of company performance. LSS as a synthesis of these methods brings significant advantages to companies operating in logistics services.

\subsection{Artificial Neural Networks}

Currently used management tools include artificial neural networks (ANN). They are based on biological learning patterns. Their advantage is the ability to work with large data volumes with very accurate prediction results (Vrbka \& Rowland, 2019; Vochozka et al., 2019). In practice, the results of NN are applicable in all areas of life; it is even possible to predict potential development of share prices (Vochozka \& Horák, 2019; Vochozka et al., 2020). As Kolkova (2020) adds, due to globalization and digitization, accurate prediction results of future variables are necessary to maintain competitiveness. The disadvantage of their application, especially of convolutional neural networks, are considerable hardware demands on the level of computational systems and longer data processing time (Jan \& Verma, 2020). It can thus be stated that NN can be used without any limitation for the companies operating in the service sector. Chung \& Jung (2020) predict that their proposed dynamic cluster model based on NN and in general, technologies obtaining knowledge from unstructured information will be the basic tools to support the development and management of health care. In the financial sector, specifically on the example of European open economy, the application of NN and logistic regression enables predicting bankruptcy as early as ten years before it really occurs (Altman et al., 2020). According to Horak et al. (2020), predicting bankruptcy is always a topical issue. For its predicting, they test the 
NN tools and Support Vector Machine. NN can also help to identify the preferences of bank clients (Ilie et al., 2017). A suitable tool to determine the creditworthiness of loan applicants is FLANN (Functional Link Artificial Neural Network). FLANN is able to help mortgage lenders to decide whether to approve or reject the application. Chang et al. (2020) compare 113685 reviews from the web TripAdvisor. Using the convolutional model of NN and its deep learning, they monitor the complementarity of various types of data. This outperforms simple data comparison. The resulting visualization of data can help hotel managers to determine business strategies based on analysing feedback provided by hotel service users. A similar methodology (using user reviews available on the web TripAdvisor) is used by Khorsand et al. (2020). Kim (2018) points to the importance of predicting future financial problems. It can be stated that predicting financial distress has a significant impact on deciding about loans and the profitability of hospitality companies and hotels. He thus proposes a cost-oriented set SVM-NN-DT as an effective method of early warning of financial distress of hotels and hospitality companies.

\subsection{Fuzzy Approach in Management in Tourism}

Tourism is an important part of the national economy. Based on a region of a country, tourism represents a significant source of income. An increase in tourism leads to the expansion of the supply of hotel services (Larrinaga \& Vallejo, 2021). This statement can be applied globally as well; especially in the second half of the $20^{\text {th }}$ century, tourism experienced a boom. Its influence is very significant in tourist destinations, which is reflected in the growth of the national GDP (Saridogan, 2020). The attempts to measure benefits of tourism qualitatively and quantitatively using classical methods do not make much sense as individual indicators (the input data) contain many inaccuracies caused by the "inner" uncertainty; therefore, the findings obtained contain uncertainty hidden in individual input indicators (Shaikh et al., 2017). This requires the application of tools that are more suitable for solving problems related to uncertainty.

The fuzzy approach has proved to be a suitable tool to measure tourism in terms of sustainable development as shown by Ziyadin et al. (2019). Here, a new approach to selecting strategic installations in the functioning of the tourism industry was applied, within which the economic-mathematical fuzzy model of management of sustainable development of tourism industry was created.

A novel approach to forecasting the success of a newly launched service in tourism by using a hybrid intelligence system called the Adaptive Neuro Fuzzy Inference System was described by Atsalakis et al. (2018). The advantage of the method lies in utilizing the combination of both the learning ability of a neural network and the reasoning ability of fuzzy logic in order to provide an improved predictive ability compared to the application of a single method. The inputs for the model were obtained from the questionnaire data that contained the variables of the new service development in tourism. The prediction accuracy of the method was evaluated by calculating performance measures. The results showed that this procedure captured uncertainty in the relationships between the input and output data to forecast the success of launching a new tourism service. Compared to other methodologies, the proposed approach proved to be the most successful.

Tourism is an energy-intensive economic sector, which is expected to play a role in reducing CO2 emissions. However, low-carbon tourism in most destinations is neglected. As Zhang (2017) points out, this can be seen e.g. in the Chinese Chengguan District of Lhasa, which has ambitions to become a world tourism centre. The author created a study based on fuzzy Delphi-ANP approach to suggest which low-carbon tourism strategy should be adopted in Chengguan District 
in forthcoming years. The priorities of low-carbon tourism strategies in Chengguan District were identified (economic development, environmental construction and social support). The study particularly stresses the importance of the indicators for tourism carbon intensity, lowcarbon transportation, education regarding a low-carbon environment, carbon sink density, and wastewater treatment in order to call for the immediate implementation and development of low-carbon tourism.

Tian et al. (2020) developed an integrated decision-making method for the assessment of environmental impact of tourism attractions in China by using an improved method of analytic hierarchy process and the extended picture fuzzy preference method for enrichment evaluations, the so-called PROMETHEE II method. The picture fuzzy method numbers were used to describe decision-makers' preference that capture uncertain and vague information in the decision-making process. Based on the results of the improved analytic hierarchy process method and the picture fuzzy method the assessment of candidate tourism attractions was performed.

The research study by Correia et al. (2019) investigated whether certain conditions can encourage tourists to buy luxury products. The results were obtained from the fuzzy-set qualitative comparative analysis; they showed that a combination of four conditions can motivate tourists to buy products of luxury brands (fashion leadership, prestige sensitivity, emotional attachment, and social value). Based on the fuzzy-set procedure, the study demonstrated that tourists who score highly in all four conditions form nearly a perfect subcategory of luxury buyers.

\subsection{Brief Insight into Fuzzy Set Theory}

The fuzzy approach has its foundations in various versions of fuzzy logic, which were created by adapting the binary numerical characteristics of propositional operators to the interval $\langle 0,1\rangle$. If $|A| \in\{0,1\}$, respectively $|B| \in\{0,1\}$, is the truth value of the statement $A$, respectively $B$, we can express the classical truth tables for negation, conjunction, disjunction and implication by numerical characteristics of these operators (Běhounek \& Cintula, 2006):

$$
\begin{aligned}
& |\neg A|=1-|A|, \\
& |A \wedge B|=\min \{|A|,|B|\}, \\
& |A \vee B|=\max \{|A|,|B|\} \\
& |A \rightarrow B|=1 \text { for }|A| \leq|B|,|A \rightarrow B|=1-(|A|-|B|), \text { otherwise. }
\end{aligned}
$$

By moving from the set $\{0,1\}$ to the interval $\langle 0,1\rangle$ we obtain the semantic form of Lukasiewicz's fuzzy propositional calculus, originally formulated by Lukasiewicz and Tarski (Peregrin \& Svoboda, 2016), applied in the theory of fuzzy sets. The basic rule of fuzzy logic in the selection of the considered alternatives is that the highest truth-value statements are preferred.

\subsection{Formal Description of Fuzzy Approach to Solving Managerial Problems}

A detailed formal description of individual steps of the fuzzy approach within the process of linguistic decision analysis in the context of multi-criteria decision-making is presented in Herrera \& Herrera-Viedma (2000). The basic procedure involves the following basic phases (see also Fig. 1): 
Phase One: The fuzzification of the numerical vector $x=\left(x_{1}, \ldots, x_{\mathrm{n}}\right)$ entering the relation in which the vector $x$ selects inferential rules relevant to its multi-criteria evaluation. These are the rules $\left(\left(\mathrm{A}_{1 \mathrm{i}}, \ldots, \mathrm{A}_{\mathrm{nj}}\right), \mathrm{B}_{\mathrm{k}}\right) \in P$, in which terms' formalizations $\mathrm{A}_{1 \mathrm{i}}, \ldots, \mathrm{A}_{\mathrm{nj}}$ of the left side are all nonzero numbers $\mu_{\underline{A}} l i\left(\chi_{1}\right), \ldots, \mu_{\underline{A} n j}\left(\chi_{\mathrm{n}}\right)$.

Phase Two: Moving from the symbolic notation $\left(\left(\mathrm{A}_{1 \mathrm{i}}, \ldots, \mathrm{A}_{\mathrm{nj}}\right), \mathrm{B}_{\mathrm{k}}\right)$ of the selected inference rule to its logic notation dependent on $x$ in the form of $\left(\min \left\{\mu_{\underline{A}} l i\left(x_{1}\right), \ldots, \mu_{\underline{A}} j\left(x_{\mathrm{n}}\right)\right\}, \mu_{\underline{B} \mathrm{k}}\right)=\left(\mu_{\underline{\underline{A}}}^{*}\right.$ $\left.(x), \mu_{\underline{B} k}\right)$, we obtain a number $\mu_{\underline{A}^{*}}(x)$ indicating not only the degree of truthfulness that the situation characterized by the vector $x$ actually occurred, and therefore, the degree of eligibility of the rule selection $\left(\left(\mathrm{A}_{1 \mathrm{i}}, \ldots, \mathrm{A}_{\mathrm{nj}}\right), \mathrm{B}_{\mathrm{k}}\right)$ to its solution, but also the degree of significance of the term $\mathrm{B}_{\mathrm{k}}$ in the multi-criteria evaluation of the vector $x . \mu_{\underline{B} k}: Y \rightarrow\langle 0,1\rangle$ is the standard membership function of the elements $y \in Y$ to the fuzzy set $\underline{B} k$. On the other hand, $\mu_{\underline{B}} k^{*} Y \rightarrow$ $\langle 0,1\rangle$ in the form of $\mu_{\underline{B} k}(y)=\min \left\{\mu_{\underline{A}^{*}}(x), \mu_{\underline{B} k}(y)\right\}$ limits from above the function $\mu_{\underline{B} k}$ by means of the number $\mu \underline{A}^{*}(x)$.

Phase Three: The components of the relation $K$ will then be the elements of the set $P x=$ $\left\{\mathrm{B}_{\mathrm{k}}: \exists y:\left(\min \left\{\mu_{\underline{A}^{*}}(x), \mu_{\underline{B} k}(y)\right\}>0\right),\left(\left(\mathrm{A}_{1 \mathrm{i}}, \ldots, \mathrm{A}_{\mathrm{nj}}\right), \mathrm{B}_{\mathrm{k}}\right) \in P, y \in Y\right\}$. These are the partial intermediate results by which aggregation (logical sum) we obtain the formalized term $\underline{B}_{a g g}=$ $\left\{\left(y, \mu_{a g g}(y)\right): y \in Y\right\}$ on $Y$, for which it holds that (1)

$$
\mu_{a g g}(y)=\max \left\{\min \left\{\mu_{\underline{A}^{*}}(x), \mu_{\underline{B} k}(y)\right\}:\left(\left(A_{1 \mathrm{i}}, \ldots, A_{\mathrm{nj}}\right), B_{k}\right) \in P, y \in Y\right\}
$$

Phase Four: The final phase of the fuzzy approach is defuzzification, whose last step provides the output value $y_{x}$ of the multicriteria model of an alternative evaluation $\left(a_{1}, \ldots, a_{c}\right) \in A$ as the mean value of the elements $y \in B_{\text {agg }}$ weighted by the values $\mu_{a g g}(y)$ of their significance - see (2). Therefore:

$$
y_{x}=\int y \cdot \mu_{a g g}(y) d y / \int \mu_{a g g}(y) d y
$$

where $\int$ is the symbol of a definite integral over the universe $Y$ - more in detail in Dubois \& Prade (1996).

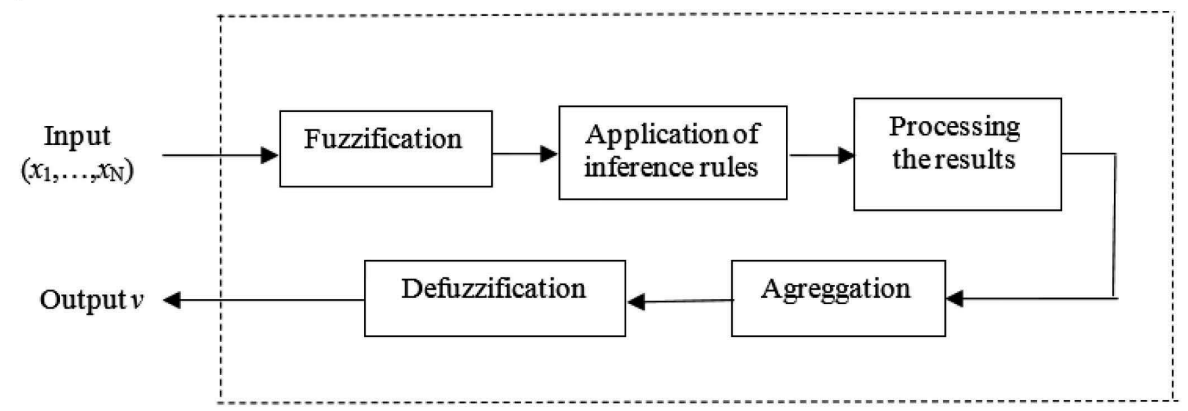

Figure 1. Schematic representation of the problem solving process using fuzzy approach

\section{FUZZY APPROACH METHOD IN THE APPLICATION}

The fuzzy procedure of a country travel and tourism competitiveness evaluation is applied from the viewpoint of travelling persons. The fuzzy approach takes into account the uncertainty of the input data contained in the indexes of ratings (Manns, 2013) and the uncertainty and complexity of vague sociological and psychological factors (Munda et al., 1995) as well as expert knowledge and experience. 


\subsection{Problem Setting and Data}

Based on the values of Travel \& Tourism Policy and Enabling Conditions (P), Natural and Cultural Resources (R) and Safety and Security (S) published by Calderwood \& Soshkin, (2019), as we can see in Table 1, the selected European and Asian countries can be divided into three categories (countries with high travel \& tourism competitiveness, countries with conditional travel \& tourism competitiveness, and countries with low travel \& tourism competitiveness) based on the perception of travelling persons obtained from Executive Opinion Survey as well as quantitative data obtained from other sources. The survey data was derived from the responses in the World Economic Forum's Executive Opinion Survey and their values range from 1 (the worst) to 7 (the best).

Table 1. Values of indexes of Travel \& Tourism Policy and Enabling Conditions, Natural and Cultural Resources and Safety and Security of selected countries in 2019

\begin{tabular}{|c|l|l|l|}
\hline Country/Index & $\begin{array}{c}\text { Travel \& Tourism Policy and } \\
\text { Enabling Conditions (P) } \\
\text { Score / Percentage rate }\end{array}$ & $\begin{array}{c}\text { Natural and Cultural } \\
\text { Resources (R) } \\
\text { Score / Percentage rate }\end{array}$ & $\begin{array}{l}\text { Safety and Security (S) } \\
\text { Score / Percentage rate }\end{array}$ \\
\hline Czech Republic & $4.7 / 67 \%$ & $2.5 / 36 \%$ & $6.1 / 87 \%$ \\
\hline China & $4.3 / 61 \%$ & $6.1 / 87 \%$ & $5.6 / 80 \%$ \\
\hline $\begin{array}{c}\text { Bosnia and } \\
\text { Herzegovina }\end{array}$ & $4.1 / 59 \%$ & $1.7 / 24 \%$ & $5.4 / 77 \%$ \\
\hline Russia & $4.4 / 60 \%$ & $3.8 / 54 \%$ & $5.1 / 73 \%$ \\
\hline Turkey & $4.5 / 64 \%$ & $3.3 / 47 \%$ & $3.4 / 49 \%$ \\
\hline
\end{tabular}

Note: Rating data are at the evaluation scale $1-7$, where 1 represents the worst and 7 the best score; for the purpose of further processing, the absolute values are converted to a percentage scale at the interval $\langle 0,100\rangle \%$.

Source: Calderwood \& Soshkin, 2019; own processing.

A direct relationship between the values of the indicators that are considered determinants of the level of travel and tourism competitiveness of a country has not been identified. However, vague practices exist for estimating the level of travel and tourism competitiveness from the values of these determinants. Moreover, an immediate relationship between the level of travel and tourism competitiveness and popularity of the country is also known. This enables us to solve the given task in two steps: The first step is the fuzzy estimation of travel and tourism competitiveness level; the second step utilizes the estimation results to allocate the country into a relevant category according to the destination popularity.

\subsection{Results}

The task consists of the separation of elements in a selected sample of countries into classes (travel and tourism competitiveness level) identified by a trio of classifiers (rating indices $-\mathrm{P}$, $\mathrm{R}, \mathrm{S}$ ), which is a standard task of discriminant analysis; however, both the functions of the classifiers and the classes are defined vaguely, which makes it non-standard. Therefore, the task is solved using the established fuzzy approach described in Fig. 1, which captures the individual steps within the fuzzy process. This is preceded by a phase of a fuzzy model formulation, which is specified as follows:

Three input linguistic variables $\mathrm{A} i, \mathrm{i} \in\{\mathrm{P}, \mathrm{R}, \mathrm{S}\}$ with value domains $U_{\mathrm{Ai}}=\langle 0,100\rangle \%$, the identified basis values of which are the numbers presented in separate columns of Table 1 . The task is to estimate the individual basic values of output linguistic variable B (travel and tourism competitiveness level) at the value domain $U_{\mathrm{B}}=\langle 0,100\rangle \%$. For linguistic terms Aik of the variable $\mathrm{Ai}$, and $\mathrm{Bj}$ of the variable $\mathrm{B}$ and for their formalized terms (fuzzy sets) $\underline{A} i k$, and $\underline{B} j$ it 
holds true that $\mathrm{j}=\mathrm{k}, \mathrm{k} \in\{\mathrm{L}, \mathrm{M}, \mathrm{H}\}$. For practical reasons, Ai, Aik, and $\underline{A} i k$ will be replaced by $\mathrm{i}, \mathrm{ki}$, and $\underline{k i}, \mathrm{~B}$ and $\underline{B j}$ by $\mathrm{O}$ and $\underline{k O}$.

The files of fuzzy sets $\underline{k i}=\left\{\left\{\left(x, \mu_{k i}(x)\right): x \in U \mathrm{i}\right\}, \mathrm{k} \in\{\mathrm{L}, \mathrm{M}, \mathrm{H}\}, \mathrm{I} \in\{\mathrm{P}, \mathrm{R}, \mathrm{S}\}\right.$ or the file $\underline{k O}=$ $\left\{\left(p, \mu_{k O}(p)\right): p \in U_{O}\right\}$ can be an acceptable choice, in which the designation $\mathrm{L}$ means a low value of linguistic variable, $\mathrm{M}$ a mean value and $\mathrm{H}$ a high value, defined by trapezoidal functions of affiliation $\mu_{k i}(x)$, respectively $\mu_{k o}(p)$ drawn in Fig. 2, Fig. 3, and Fig. 4.

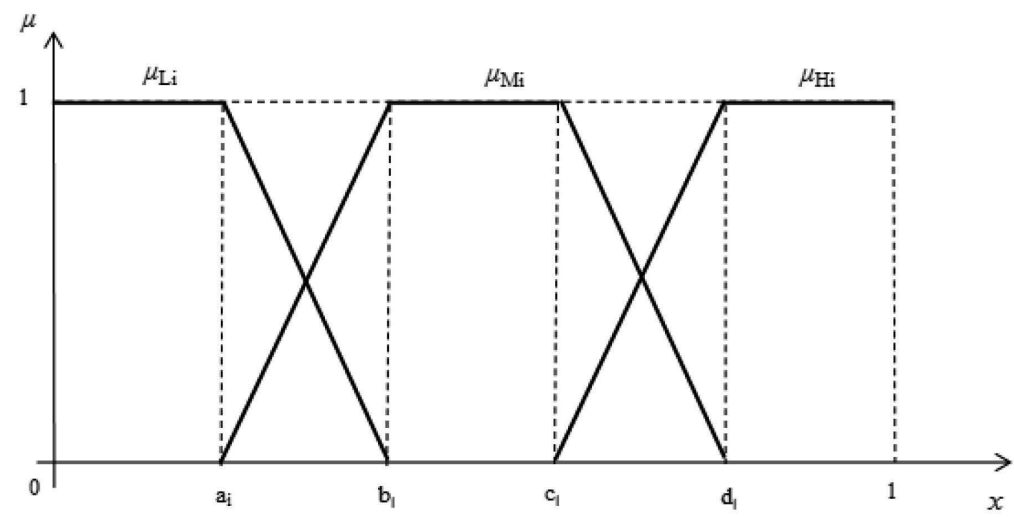

Figure 2. Courses of membership functions to terms of linguistic variable $i$, for $i \in\{P, R, S\}$

The following applies:

(Li) $\mu_{\mathrm{Li}}(x)=1$ for $0 \leq x \leq \mathrm{a}_{i}$,

$$
\mu_{\mathrm{Li}}(x)=\left(\mathrm{b}_{\mathrm{i}}-x\right) /\left(\mathrm{b}_{\mathrm{i}}-\mathrm{a}_{\mathrm{i}}\right) \text { for } \mathrm{a}_{\mathrm{i}} \leq x \leq \mathrm{b}_{\mathrm{i}},
$$$$
\mu_{\mathrm{Li}}(x)=0 \text { for } x \geq \mathrm{b}_{\mathrm{i}}
$$

$$
\begin{aligned}
& \mu_{\mathrm{Mi}}(x)=\left(x-\mathrm{a}_{\mathrm{i}}\right) /\left(\mathrm{b}_{\mathrm{i}}-\mathrm{a}_{\mathrm{i}}\right) \text { for } \mathrm{a}_{\mathrm{i}} \leq x \leq \mathrm{b}_{\mathrm{i}}, \\
& \mu_{\mathrm{Mi}}(x)=1 \text { for } \mathrm{b}_{\mathrm{i}} \leq x \leq \mathrm{c}_{\mathrm{i}}, \\
& \mu_{\mathrm{Mi}}(x)=\left(\mathrm{d}_{\mathrm{i}}-x\right) /\left(\mathrm{d}_{\mathrm{i}}-\mathrm{c}_{\mathrm{i}}\right) \text { for } \mathrm{c}_{\mathrm{i}} \leq x \leq \mathrm{d}_{\mathrm{i}}, \\
& \mu_{\mathrm{Mi}}(x)=0 \text { otherwise } \\
& \mu_{\mathrm{Hi}}(x)=0 \text { for } 0 \leq x \leq \mathrm{c}_{\mathrm{i}}, \\
& \mu_{\mathrm{Hi}}(x)=\left(x-\mathrm{c}_{\mathrm{i}}\right) /\left(\mathrm{d}_{\mathrm{i}}-\mathrm{c}_{\mathrm{i}}\right) \text { for } \mathrm{c}_{\mathrm{i}} \leq x \leq \mathrm{d}_{\mathrm{i}}, \\
& \mu_{\mathrm{Hi}}(x)=1 \text { for } x \geq \mathrm{d}_{\mathrm{i}}
\end{aligned}
$$

Various distributions of parameters $a_{i}, b_{i}, c_{i}, d_{i}$ for various $i$ on the horizontal axis in Fig. 2 represent various distributions of basic values of these variables. Table 1 shows, for example, that when $\mathrm{i}=\mathrm{P}$, none of the basic values out of these five is under the limit of $d_{i}$, whereas when $\mathrm{i}=\mathrm{S}$, three values are under this limit. For this reason, ap $<$ as should apply. Especially for $\mathrm{O}$, where the distribution is not known and where there is no reason for assuming asymmetry, $\mathrm{a}_{\mathrm{o}}=$ $20, \mathrm{~b}_{\mathrm{o}}=40, \mathrm{c}_{\mathrm{O}}=60, \mathrm{~d}_{\mathrm{O}}=80$ (see Fig. 4). By a suitable choice of these four parameters in the affiliation of functions to terms of input linguistic variables, it is possible to consider the structure of the measured or otherwise established data in the fuzzy model (this is a task for an expert). To describe the procedure of the task, all linguistic variables are assumed to have the same distribution and uniformity as the four mentioned parameters (as in the case of variable O). This distribution will vary according to the experts who decide on its parameters. 
Another step is a compilation of a set of inference rules of type $\left(\left(\underline{k_{1}} \underline{P}, \underline{k_{2}} \underline{R}, \underline{k_{3}} \underline{S}\right), \underline{k} O\right)$ for assigning three output terms to total 27 various triplets $\alpha_{3}$ of input terms, where $\mathrm{k}_{1}$, $\mathrm{k}_{2}, \mathrm{k}_{3}, \mathrm{k} \in\{\mathrm{L}, \mathrm{M}, \mathrm{H}\}$. The basic strategy is the choice of $\underline{\mathrm{kO}}$ with the $\mathrm{k}$, which prevails in the triplet $\left(\underline{k_{1}} \underline{P}, \underline{k_{2}} \underline{R}, \underline{k_{3}} \underline{S}\right)$. If none of them prevails, $\underline{M O}$ is chosen. This selection strategy assigns $\underline{M O}$ to thirteen triplets of input terms in total; $\underline{\underline{L O}}$, respectively $\underline{H O}$, is assigned in seven of the remaining cases - see Table 2 presenting the rules compiled based on this strategy, which is determined by the experts and decision makers.

Table 2. Set of twenty-seven inference rules (in the form $\mathrm{k}_{1} \mathrm{k}_{2} \mathrm{k}_{3} \rightarrow \mathrm{k}$ )

\begin{tabular}{|l|l|l|l|l|l|l|l|l|}
\hline $\mathrm{LLL} \rightarrow \mathrm{L}$ & $\mathrm{LLH} \rightarrow \mathrm{L}$ & $\mathrm{LMH} \rightarrow \mathrm{M}$ & $\mathrm{MMM} \rightarrow \mathrm{M}$ & $\mathrm{MLL} \rightarrow \mathrm{L}$ & $\mathrm{MHM} \rightarrow \mathrm{M}$ & $\mathrm{HHH} \rightarrow \mathrm{H}$ & $\mathrm{HLH} \rightarrow \mathrm{H}$ & $\mathrm{HHM} \rightarrow \mathrm{H}$ \\
\hline $\mathrm{LLM} \rightarrow \mathrm{L}$ & $\mathrm{LHL} \rightarrow \mathrm{L}$ & $\mathrm{LMM} \rightarrow \mathrm{M}$ & $\mathrm{MLM} \rightarrow \mathrm{M}$ & $\mathrm{MLH} \rightarrow \mathrm{M}$ & $\mathrm{MHH} \rightarrow \mathrm{H}$ & $\mathrm{HLL} \rightarrow \mathrm{L}$ & $\mathrm{HMM} \rightarrow \mathrm{M}$ & $\mathrm{HLM} \rightarrow \mathrm{M}$ \\
\hline $\mathrm{LML} \rightarrow \mathrm{L}$ & $\mathrm{LHM} \rightarrow \mathrm{M}$ & $\mathrm{LHH} \rightarrow \mathrm{H}$ & $\mathrm{MML} \rightarrow \mathrm{M}$ & $\mathrm{MMH} \rightarrow \mathrm{M}$ & $\mathrm{MHL} \rightarrow \mathrm{M}$ & $\mathrm{HHL} \rightarrow \mathrm{H}$ & $\mathrm{HMH} \rightarrow \mathrm{H}$ & $\mathrm{HML} \rightarrow \mathrm{M}$ \\
\hline
\end{tabular}

The specific procedure related to the fuzzy model solution shown in Fig. 1 will be explained on the example of construction of the $p_{0}$ parameter for the Czech Republic. As stated above, for the purpose of the demonstrative calculations, the differences in the distribution of values of individual indices will be ignored (for each of them the parameters of affiliation functions to terms are given as $\mathrm{a}=20 \%, \mathrm{~b}=40 \%, \mathrm{c}=60 \%, \mathrm{~d}=80 \%$ ). A triplet of input basis values $\left(x_{0}, y_{0}, z_{0}\right), x_{0} \in U_{\mathrm{P}}, y_{0} \in U_{\mathrm{R}}, z_{0} \in U_{\mathrm{S}}$ is the triplet $(67,36,87)-$ see Table 1 . Their inclusion into the respective terms is seen in Fig. 3.

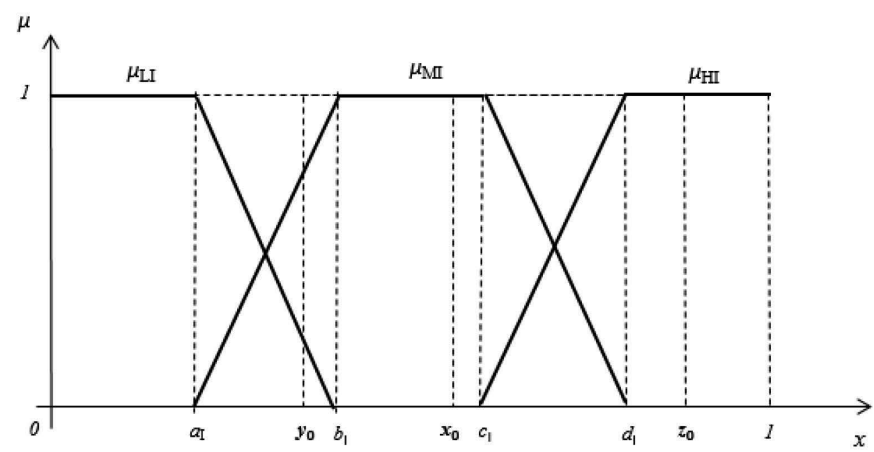

Figure 3. Graphical representation of the term assignment to the input basic values for the Czech Republic

From the calculations, it follows that (the formulas for calculation are specified below Fig. 2):

- $67 \in S_{\mathrm{MP}}$ with the truth $\left|67 \in S_{\mathrm{MP}}\right|=\mu_{\mathrm{MP}}(67)=(80-67) / 20=0.65$

- $67 \in S_{\mathrm{HP}}$ with the truth $\left|67 \in S_{\mathrm{HP}}\right|=\mu_{\mathrm{HP}}(67)=(67-60) / 20=0.35$

- $36 \in S_{\mathrm{LR}}$ with the truth $\left|36 \in S_{\mathrm{LR}}\right|=\mu_{\mathrm{LR}}(36)=(40-36) / 20=0.2$

- $36 \in S_{\mathrm{MR}}$ with the truth $\left|36 \in S_{\mathrm{MR}}\right|=\mu_{\mathrm{MR}}(36)=(36-20) / 20=0.8$

- $87 \in S_{\mathrm{HS}}$ with the truth $\left|87 \in S_{\mathrm{HS}}\right|=\mu_{\mathrm{HP}}(87)=1$.

We have finished the fuzzification process in which the assigned input values $(67,36,87)$ enabled selection of four triplets $\alpha_{3}$ in the symbolic notation $\alpha_{M M H}=(\underline{M P}, \underline{M R}, \underline{H S}), \alpha_{M L H}=$ $(\underline{M P}, \underline{L R}, \underline{H S}), \alpha_{H M H}=(\underline{H P}, \underline{M R}, \underline{H S})$ and $\alpha_{H L H}=(\underline{H P}, \underline{L R}, \underline{H S}) ;$ in the logic notation $\alpha_{\mathrm{MMH}} *=\left(67 \in S_{\mathrm{MP}}\right) \wedge\left(36 \in S_{\mathrm{MR}}\right) \wedge\left(87 \in S_{\mathrm{HS}}\right),\left|\alpha_{\mathrm{MMH}} *\right|=\min \{0.65,0.8,1\}=$ $0.65 ; \alpha_{\mathrm{MLH}} *=\left(67 \in S_{\mathrm{MP}}\right) \wedge\left(36 \in S_{\mathrm{LR}}\right) \wedge\left(87 \in S_{\mathrm{HS}}\right),\left|\alpha_{\mathrm{MLH}} *\right|=\min \{0.65,0.2,1\}=$ $0.2 ; \alpha_{\mathrm{HMH}} *=\left(67 \in S_{\mathrm{HP}}\right) \wedge\left(36 \in S_{\mathrm{MR}}\right) \wedge\left(87 \in S_{\mathrm{HS}}\right),\left|\alpha_{\mathrm{HMH}} *\right|=\min \{0.35,0.8,1\}=$ $0.35 ; \alpha_{\mathrm{HLH}^{*}}=\left(67 \in S_{\mathrm{HP}}\right) \wedge\left(36 \in S_{\mathrm{LR}}\right) \wedge\left(87 \in S_{\mathrm{HS}}\right),\left|\alpha_{\mathrm{HLH}} *\right|=\min \{0.35,0.2,1\}=0.2$. 
By the application of inference rules on the symbolic notation of triplets, the outputs $\underline{M O}$ and $\underline{H O}$ were traced by the rules

$(M P, M R, H S), M O),((M P, L R, H S), M O),((H P, M R, H S), H O)$ and $((H P, L R, H S), H O)$.

Then

$\mathrm{AGG}=$

$\left(\alpha_{\mathrm{MMH}^{*}}, p \in S_{\mathrm{MO}}\right) \vee\left(\alpha_{\mathrm{MLH}^{*}}, p \in S_{\mathrm{MO}}\right) \vee\left(\alpha \mathrm{HMH}^{*}, p \in S_{\mathrm{HO}}\right) \vee\left(\alpha \mathrm{HLH}^{*}, p \in S_{\mathrm{HO}}\right)$ and $\mu_{\mathrm{agg}}=$ $|\mathrm{AGG}|=$

$\max \left\{\min \left\{\left|\alpha_{\mathrm{MMH}} *\right|, \mu_{\mathrm{MO}}(p)\right\}, \min \left\{\left|\alpha_{\mathrm{MLH}} *\right|, \mu_{\mathrm{MO}}(p)\right\}, \min \left\{\left|\alpha_{\mathrm{HMH}} *\right|, \mu_{\mathrm{HO}}(p)\right\}, \min \left\{\left|\alpha_{\mathrm{HLH}} *\right|, \mu_{\mathrm{H}}\right.\right.$ $\left.\mathrm{o}(p)\}\}=\max \left\{\min \left\{0.65, \mu_{\mathrm{MO}}(p)\right\}, \min \left\{0.35, \mu_{\mathrm{HO}}(p)\right\}, \mu_{\mathrm{HO}}(p)\right\}\right\}$.

Then $\mu_{A G G}(y)=0.65$ for $33 \leq y<67, \mu_{A G G}(y)=0.35$ for $67 \leq y<100$ (see the bold line in Fig. 4).

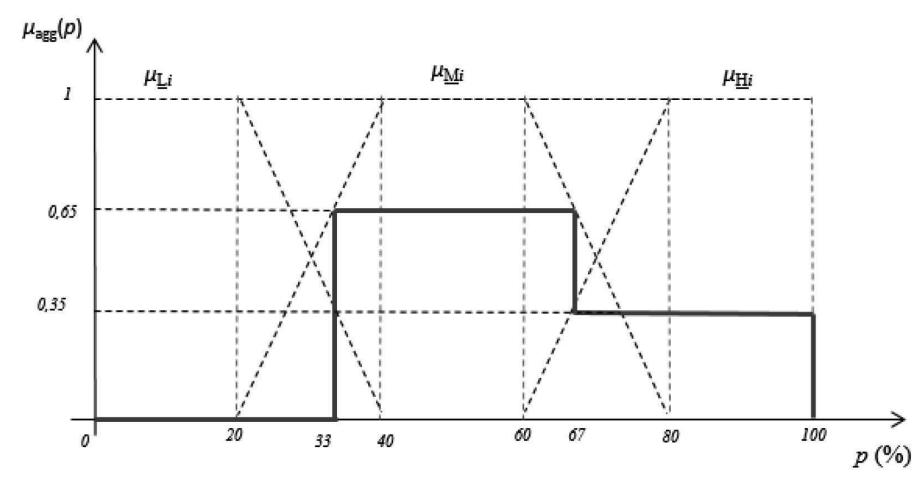

Figure 4. Graph of function $\mu_{\text {agg }}$

By a numerical approximation of the values of integrals in the formula for the calculation of the horizontal coordinate of the position of the centre of gravity (the relation (2)), the value of $p_{0}$ in $(\%)$ is assessed as

$p_{0}=(0.65 \cdot(40+50+60)+0.35 \cdot(70+80+90+100)) /(3 \cdot 0.65+4 \cdot$ $0.35)=65 \%$.

The resulting values of $p_{0}$ for all examined countries are summarized in Table 3 .

Table 3. Values of travel and tourism competitiveness index $\mathrm{p}_{0}$ (in \%)

\begin{tabular}{|c|c|}
\hline Country & Index $\boldsymbol{p}_{\mathbf{0}}$ in \% / Fuzzy score \\
\hline Czech Republic & $65 / 4.6$ \\
\hline China & $75 / 5.3$ \\
\hline Pakistan & $50 / 3.5$ \\
\hline Russia & $60 / 4.2$ \\
\hline Turkey & $55 / 3.9$ \\
\hline
\end{tabular}

\subsection{Discussion}

As stated above, there is an indirectly proportional dependence of the popularity of the country from the view of travelling persons (PC) on the travel and tourism competitiveness level (TC). When TC grows, PC increases and vice versa. From this point of view, Fig. 2 and 3 can be interpreted in such a way that in the interval $(0$, a) all experts consider TC to be low and hence PC is 
considered to be low as well. At the interval of $(a, b)$, their views differ. The number of experts who consider TC to be low decreases in favour of those who consider TC to be medium, which increases if TC moves closer to the point $b$. The same can be said about PC. In terms of the interval (b, c), all experts agree that TC and PC are medium. In the course of (c, d), the experts gradually deviate from the view that TC and PC achieve medium values and agree that TC and $\mathrm{PC}$ are high at the interval of $(\mathrm{d}, 1)$.

The boundaries between the classes of country popularity with respect to the opinion of most experts are as follows: the intersections of the curves $\mu$ of the formalized terms of the linguistic variable TC have coordinates $p_{1}[30,0.5]$ and $p_{2}[70,0.5]$, see e.g. Fig. 3. Because of their similarity to the potential curves $\mu$ of the terms of the variable PC, they can be mutually approximated.

The boundaries distinguishing the countries with high travel \& tourism competitiveness (highly popular destinations), conditional travel \& tourism competitiveness (conditionally popular destinations), and low travel \& tourism competitiveness (low popular destinations) lie at the points $p_{1}=30$ percent and $p_{2}=70$ percent. The results summarised in Tab. 3 indicate that China is ranked as a country with high travel $\&$ tourism competitiveness and a very popular tourist destination. The countries with conditional travel \& tourism competitiveness include the Czech Republic, Pakistan, Russia, and Turkey, which are considered to be medium popular with travelling persons.

For the purposes of the demonstrative task, necessary calculations are, without loss of generality, minimized by the assumption of identical courses of membership functions of formalized terms of input linguistic variables. Regardless of this simplification, the solved specific task is a useful illustration of the presented method in terms of tourism indices estimation.

\section{FUTURE RESEARCH DIRECTIONS}

Further research should be focused on the application of fuzzy approach in the broader area of tourism management. In terms of artificial intelligence and artificial neural networks, further research should be aimed at increasing awareness of these tools and their use in the service sector, which includes tourism.

\section{CONCLUSION}

The objective of the paper was to evaluate the level of travel \& tourism competitiveness of selected European and Asian countries based on the subjective ranking of travelling persons and fuzzy approach.

The theoretical part indicates that SQC used for management is one of the oldest tools; despite this, it is also currently suitable for the application in all types of companies, including those operating in the service sector. It should be added that the knowledge of statistical methods is important for management. In summary, SQC can be seen as a pioneering method that introduced a modern methodology in quality assessment in the world of management. A more recent version - TQM - is used more frequently in management compared to its predecessor; the fund of the contributions to its application in the service sector is not very rich. However, there is a large number of studies territorially focused on hotel industry in the countries of southern Europe, especially Spain. 
Currently, one of the most widely used tools to measure quality is Six Sigma, which was created by the management of the multinational corporation Motorola. For company management, before the implementation of the Six Sigma method, it is very important to accept its tools; however, the individual acceptance of Six Sigma in companies has been little addressed in the studies. The application of Six Sigma can be a turning point for companies within their life cycle. Six Sigma has the potential to increase innovations, improve financial performance and skills of employees. In the service sector, Six Sigma can be applied to improve the quality of teaching within the tertiary education, etc. In tourism, there can be mentioned e.g. the introduction of Six Sigma in the company Starwood Hotels and Resorts. In 2001, LSS appeared as a modification of Six Sigma. LSS has a similar application and methodology as the basic Six Sigma; the difference is in the concept of LSS, which is a synthesis with lean thinking. LSS improves processes in state administration, logistics, education, etc.

Modern management tools are based on computer technology. They include also ANN, whose main advantage is their ability to work with large volume of data and relatively accurate predictions of various phenomena for the future. The main disadvantage is required hardware and longer data processing time. In the service sector, ANN can be used for predicting bankruptcy, determining the creditworthiness of entities applying for mortgage loans, optimization of processes in health care, tourism, etc. From the portal TripAdvisor, user reviews are collected, which are integrated in the ANN system. The prediction results should lead to better business performance. In the case of ANN, it should be taken into account that for most companies, it is a theoretical tool. Their wide application in tourism is expected rather in the future, although a number of companies operating in this sector have already been using artificial neural networks. The authors believe that the development and application of artificial intelligence in tourism will contribute to improving the situation concerning the problems arising with the current coronavirus pandemic.

The paper focused on the fuzzy approach method in more detail at the theoretical and application level. The fuzzy approach provides space for the application of the human factor. It is widely used for the evaluation of problems and issues concerning travel and tourism sector. It is based on the assumption that the key elements of human thinking are not numbers but intuitive concepts, the contents of which can be modelled by fuzzy sets. Herein, the fuzzy approach was used to assess the travel \& tourism competitiveness level, the solution of which was obtained by a "detour" over vaguely defined procedures. The results indicate that within the countries under review, China is ranked as a country with high travel \& tourism competitiveness and a very popular tourist destination. The countries with conditional travel \& tourism competitiveness include the Czech Republic, Pakistan, Russia, and Turkey, which are considered to be medium popular with travelling persons.

\section{REFERENCES}

Altman, E. I., Iwanicz-Drozdowska, M., Laitinen, E. K., \& Suvas, A. (2020). A race for long horizon bankruptcy prediction. Applied Economics, 52(37), 4092-4111. https://doi.org/10.1 080/00036846.2020.1730762.

Antony, J., Rodgers, B., \& Cudney, E. A. (2019). Lean Six Sigma in policing services: Case examples, lessons learnt and directions for future research. Total Quality Management \& Business Excellence, 30(5-6), 613-625. https://doi.org/10.1080/14783363.2017.1327319.

Atsalakis, G. S., Atsalaki, I. G., \& Zopounidis, C. (2018). Forecasting the success of a new tourism service by a neuro-fuzzy technique. European Journal of Operational Research, 268(2), 716-727. https://doi.org/10.1016/j.ejor.2018.01.044. 
Běhounek, L., \& Cintula, P. (2006). From fuzzy logic to fuzzy mathematics: A methodological manifesto. Fuzzy Sets and Systems, 157(5), 642-646. https://doi.org/10.1016/j. fss.2005.10.011.

Benavides-Valesco, C. A., Quintana-Garcia, C., \& Marchante-Lara, M. (2014). Total quality management, corporate social responsibility and performance in the hotel industry. International Journal of Hospitality Management, 41, 77-87. https://doi.org/10.1016/j. ijhm.2014.05.003.

Boyapati, S. R., \& Kantam, R. R. L. (2012). Extreme value charts and analysis of means based on half logistic distribution. International Journal of Quality \& Reliability Management, 29(5), 501-511. https://doi.org/10.1108/02656711211230490.

Calderwood, L. U., \& Soshkin, M. (2019). The travel \& tourism competitiveness report 2019. In K. Schwab, A. Menon \& C. Wolff (Eds.), World Economic Forum (pp. 1-112). Geneva: The World Economic Forum. http://www3.weforum.org/docs/WEF_TTCR_2019.pdf.

Chakraborty, A., \& Tan, K. C. (2012). Case study analysis of Six Sigma implementation in service organisations. Business Process Management Journal, 18(6), 992-1019. https://doi. org/10.1108/14637151211283384.

Chang, Y. C., Ku, C. H., \& Chen, C. H. (2020). Using deep learning and visual analytics to explore hotel reviews and responses. Tourism Management, 80. https://doi.org/10.1016/j. tourman.2020.104129.

Chung, K. Y., \& Jung, H. (2020). Knowledge-based dynamic cluster model for healthcare management using a convolutional neural network. Information Technology and Management, 21(1), 41-50. https://doi.org/10.1007/s10799-019-00304-1.

Coldrick, S., Longhurst, P., Ivey, P., \& Hannis, J. (2005). An R\&D options selection model for investment decisions. Technovation, 25(3), 185-193. https://oi.org/10.1016/S01664972(03)00099-3.

Correia, A., Kozak, M., \& Kim, S. (2019). Investigation of luxury values in shopping tourism using a fuzzy-set approach. Journal of Travel Research, 58(1), 77-91. https://doi. org $/ 10.1177 / 0047287517741005$.

Cudney, E. A., Venuthurumilli, S. S. J., Materla, T., \& Antony, J. (2020). Systematic review of Lean and Six Sigma approaches in higher education. Total Quality Management \& Business Excellence, 31(3-4), 231-244. https://doi.org/10.1080/14783363.2017.1422977.

Dubois, D., \& Prade, H. (1996). What are fuzzy rules and how to use them. Fuzzy sets and systems, 84(2), 169-185. https://doi.org/10.1016/0165-0114(96)00066-8.

Fletcher, J. (2018). Opportunities for Lean Six Sigma in public sector municipalities. International Journal of Lean Six Sigma, 9(2), 256-267. https://doi.org/10.1108/IJLSS-07-2017-0086.

Ghassan, G., Maelah, R., Amir, A. M., \& Farhan, M. F. (2019). Total quality management and the role of management accountants on organisational performance: The service sector in Malaysia. Asian Journal of Business and Accounting, 12(2), 147-177. https://doi.org/10.22452/ ajba.vol12 no2.6.

Grigg, N. P., \& Walls, L. (2007). Developing statistical thinking for performance improvement in the food industry. International Journal of Quality \& Reliability Management, 24(4), 347-369. https://doi.org/10.1108/02656710710740536.

Gupta, S. K., Antony, J., Lacher, F., \& Douglas, J. (2020). Lean Six Sigma for reducing student dropouts in higher education - an exploratory study. Total Quality Management \& Business Excellence, 31(1-2), 178-193. https://doi.org/10.1080/14783363.2017.1422710.

Gutierrez-Gutierezz, L., De Leeuw, S., \& Dubbers, R. (2016). Logistics services and Lean Six Sigma implementation: A case study. International Journal of Lean Six Sigma, 7(3), 324342. https://doi.org/10.1108/IJLSS-05-2015-0019. 
Herrera, F., \& Herrera-Viedma, E. (2000). Linguistic decision analysis: steps for solving decision problems under linguistic information. Fuzzy Sets and Systems, 115(1), 67-82. https:// doi.org/10.1016/S0165-0114(99)00024-X.

Horak, J., Vrbka, J., \& Suler, P. (2020). Support vector machine methods and artificial neural networks used for the development of bankruptcy prediction models and their comparison. Journal of Risk and Financial Management, 13(3). https://doi.org/10.3390/jrfm13030060.

Ilie, M., Moraru, A. D., \& Ghita-Mitrescu, S. (2017). The hierarchical determination of customer satisfaction with banking services using an artificial neural network. Transformations in Business \& Economics, 16(2A), 401-420.

Jan, Z., \& Verma, B. (2020). Multiple strong and balanced cluster-based ensemble of deep learners. Pattern Recognition, 107. https://doi.org/10.1016/j.patcog.2020.107420.

John, B., \& Kadadevaramath, R. S. (2020). Improving the resolution time performance of an application support process using Six Sigma methodology. International Journal of Lean Six Sigma, 11(4), 663-686. https://doi.org/10.1108/IJLSS-10-2018-0108.

Jovanović, P. (1999). Application of sensitivity analysis in investment project evaluation under uncertainty and risk. International Journal of project management, 17(4), 217-222. https:// doi.org/10.1016/S0263-7863(98)00035-0.

Jusoh, A., Mardani, A., Omar, R., Streimikiene, D., Khalifah, Z., \& Sharifara, A. (2018). Application of MCDM approach to evaluate the critical success factors of total quality management in the hospitality industry. Journal of Business Economics and Management, 19(2), 399-416. https://doi.org/10.3846/jbem.2018.5538.

Khorsand, R., Rafiee, M., \& Kayvanfar, V. (2020). Insights into TripAdvisor's online reviews: The case of Tehran's hotels. Tourism Management Perspectives, 34. https://doi.org/10.1016/j. tmp.2020.100673.

Kim, S. Y. (2018). Predicting hospitality financial distress with ensemble models: The case of US hotels, restaurants, and amusement and recreation. Service Business, 12(3), 483-503. https://doi.org/10.1007/s11628-018-0365-x.

Kolkova, A. (2020). The application of forecasting sales of services to increase business competitiveness. Journal of Competitiveness, 12(2), 90-105. https://doi.org/10.7441/joc.2020.02.06.

Kuvvetli, U., \& Firuzan, A. R. (2019). Applying Six Sigma in urban public transportation to reduce traffic accidents involving municipality buses. Total Quality Management \& Business Excellence, 30(1-2), 82-102. https://doi.org/10.1080/14783363.2017.1297198.

Larrinaga, C., \& Vallejo, R. (2021). The origins and creation of the tourist hotel industry in Spain from the end of the 19th century to 1936. Barcelona as a case study. Tourism Management, 82. https://doi.org/10.1016/j.tourman.2020.104203.

Manns, J. (2013). Downgrading rating agency reform. George Washington Law Review, 81(3), 749. https://papers.ssrn.com/sol3/papers.cfm?abstract_id=2174802.

Miranti, P. J. (2005). Corporate learning and quality control at the Bell System, 1877-1929. Business History Review, 79(1), 39-72. https://doi.org/10.1017/S0007680500080193.

Mueller, P. S., Cross, J. A. (2020). Factors impacting individual Six Sigma adoption. International Journal of Lean Six Sigma, 11(1), 57-83. https://doi.org/10.1108/IJLSS-04-2018-0040.

Munda, G., Nijkamp, P., \& Rietveld, P. (1995). Qualitative multicriteria methods for fuzzy evaluation problems: An illustration of economic-ecological evaluation. European Journal of Operational Research, 82(1), 79-97. https://doi.org/10.1016/0377-2217(93)E0250-2.

Ninerola, A., Sanchez-Rebull, M. V., \& Hernandez-Lara, A. B. (2019). Mapping the field: relational study on Six Sigma. Total Quality Management \& Business Excellence. https://doi. org/10.1080/14783363.2019.1685864. 
Omrane, H., Masmoudi, M. S., \& Masmoudi, M. (2016). Fuzzy logic based control for autonomous mobile robot navigation. Computational Intelligence and Neuroscience, 2016. https://doi.org/10.1155/2016/9548482.

Oprime, P. C., Pimenta, M. L., Jugend, D., \& Andersson, R. (2019). Financial impacts of innovation in Six Sigma projects. Total Quality Management \& Business Excellence. https:// doi.org/10.1080/14783363.2019.1641076.

Pearlman, D. M., \& Chacko, H. (2012). The quest for quality improvement: Using Six Sigma at Starwood hotels and resorts. International Journal of Hospitality \& Tourism Administration, 13(1), 48-66. https://doi.org/10.1080/15256480.2012.640212.

Peregrin, J., \& Svoboda, V. (2016). Logical formalization and the formation of logic(S). Logique et Analyse, 59(233), 55-80. https://doi.org/10.2143/LEA.233.0.3149531.

Saridogan, H. O. (2020). The impacts of tourism revenues on economic growth: Unit root and cointegration tests with structural break for Turkey. Eskisehir Osmangazi Universitesi Iibf Dergisi-Eskisehir Osmangazi University Journal of Economics and Administrative Sciences, 15(3), 829-848.

Schwartz, E. S., \& Zozaya-Gorostiza, C. (2002). Evaluating investments in disruptive technologies. In H. Geman, D. Madan, S. R. Pliska \& T. Vorst (Eds.), Mathematical Finance-Bachelier Congress 2000 (pp. 463-486). Berlin, Heidelberg: Springer. https://doi. org/10.1007/978-3-662-12429-1_21.

Sevinc, A., Gür, Ş., \& Eren, T. (2018). Analysis of the difficulties of SMEs in industry 4.0 applications by analytical hierarchy process and analytical network process. Processes, 6(12). https://doi.org/10.3390/pr6120264.

Shaikh A.A., Glavee-Geo R., \& Karjaluoto H. (2017). Exploring the nexus between financial sector reforms and the emergence of digital banking culture - Evidences from a developing country. Research in International Business and Finance, 42, 1030-1039. https://doi. org/10.1016/j.ribaf.2017.07.039.

Sony, M., Antony, J., Park, S., \& Multingi, M. (2020). Key criticisms of Six Sigma: A systematic literature review. IEEE Transactions on Engineering Management, 67(3), 950-962. https:// doi.org/10.1109/TEM.2018.2889517.

Tari, J. J., Pereira-Moliner, J., Pertusa-Ortega, E. M., Lopez-Gamero, M. D., \& Molina-Azori, J. F. (2017). Does quality management improve performance or vice versa? Evidence from the hotel industry. Service Business, 11(1), 23-43. https://oi.org/10.1007/s11628-015-0298-6.

Tian, C., Peng, J., Zhang, W., Zhang, S., \& Wang, J. (2020). Tourism environmental impact assessment based on improved AHP and picture fuzzy PROMETHEE II methods. Technological and Economic Development of Economy, 26(2), 355-378. https://doi.org/10.3846/ tede.2019.11413.

Vaishnavi, V., \& Suresh, M. (2020). Assessment of readiness level for implementing lean six sigma in healthcare organization using fuzzy logic approach. International Journal of Lean Six Sigma. https://doi.org/10.1108/IJLSS-07-2019-0081.

Vochozka, M., \& Horak, J. (2019). Comparison of neural networks and regression time series when estimating the copper price development. In S. Ashmarina \& M. Vochozka (Eds.), Sustainable Growth and Development of Economic Systems: Contradictions in the Era of Digitalization and Globalization; Contributions to Economics (pp. 169-181). Cham, Switzerland: Springer. https://doi.org/10.1007/978-3-030-11754-2_13.

Vochozka, M., Horak, J., \& Krulicky, T. (2020). Innovations in management forecast: Time development of stock prices with neural networks. Marketing and Management of Innovation, 2, 324-339. http://doi.org/10.21272/mmi.2020.2-24. 
Vochozka, M., Horak, J., \& Suler, P. (2019). Equalizing seasonal time series using artificial neural networks in predicting the Euro-Yuan exchange rate. Journal of Risk and Financial Management, 12(2). https://doi.org/10.3390/jrfm12020076.

Vrbka, J., \& Rowland, Z. (2020). Using artificial intelligence in company management. In S. Ashmarina, M. Vochozka \& V. V. Mantulenko (Eds.), Digital Age: Chances, Challenges and Future; Lecture Notes in Networks and systems (pp. 422-429). Cham, Switzerland: Springer, (pp. 241-220). https://doi.org/10.1007/978-3-030-27015-5_51.

Zadeh, L. A. (1973). Outline of a new approach to the analysis of complex systems and decision processes. IEEE Transactions on systems, Man, and Cybernetics, (1), 28-44. https://doi. org/10.1109/TSMC.1973.5408575.

Zadeh, L. A. (1999). Fuzzy logic = computing with words. In L. A. Zadeh \& J. Kacprzyk (Eds.), Computing with Words in Information/Intelligent Systems 1 (pp. 3-23). Heidelberg: Physica, Springer. https://doi.org/10.1007/978-3-7908-1873-4_1.

Zhang, C., Moreira, M. R. A., \& Sousa, P. S. A. (2020). A bibliometric view on the use of total quality management in services. Total Quality Management \& Business Excellence. https://doi.org/10.1080/14783363.2020.1732811.

Zhang, J. (2017). Evaluating regional low-carbon tourism strategies using the fuzzy Delphi-analytic network process approach. Journal of Cleaner Production, 141, 409-419. https://doi. org/10.1016/j.jclepro.2016.09.122.

Ziyadin, S., Borodin, A., Streltsova, E., Suieubayeva, S., \& Pshembayeva, D. (2019). Fuzzy logic approach in the modeling of sustainable tourism development management. Polish Journal of Management Studies, 19(1), 492-504. https://doi.org/10.17512/pjms.2019.19.1.37. 
